\title{
An assessment of risk of iodine deficiency among pregnant women in Sarawak, Malaysia
}

\author{
Lim Kuang Kuay ${ }^{1}$, Tan Beng Chin ${ }^{2}$, Mohd Shaiful Azlan Kassim ${ }^{3}$, Nur Azna Mahmud ${ }^{4}$, Ruhaya \\ Salleh $^{5}$, Cheong Siew Man ${ }^{6}$, Norazizah Ibrahim Wong ${ }^{7}$, Chan Ying Ying ${ }^{8}$, Tahir Aris ${ }^{9}$ \\ 1,3,4,5,6,7,8,9 Institute for Public Health, Ministry of Health, Malaysia \\ ${ }^{2}$ Nutrition Unit, Sarawak State Health Department, Ministry of Health, Malaysia
}

\section{Article Info}

Article history:

Received Jun 4, 2019

Revised Jul 21, 2019

Accepted Aug 22, 2019

\section{Keywords:}

Iodine deficiency disorders

Iodized salt

Pregnant women

Sarawak

\begin{abstract}
Previous findings from a state-wide Iodine Deficiency Disorders (IDD) study among pregnant women (PW) in Sarawak indicated that PW are at risk of IDD and further study is needed. This paper describes the methodology used in conducting this study on assessment of risk of iodine deficiency among pregnant women in Sarawak, Malaysia. Thirty maternal child health care clinics (MCHCs) were selected using probability proportional to population size (PPS) sampling technique. The PW sample size was calculated based on $95 \%$ confidence interval (CI), relative precision of $5 \%$, design effect of 2 , anticipated IDD prevalence of $65.0 \%$ and non-response rate of $20 \%$. Thus, the total sample size required was 750 (25 respondents per selected MCHC). The WHO Expanded Programme on Immunization (EPI) surveys approach was used to randomly select the first respondent and subsequent respondents were chosen until the required number of PW was met. The required data were obtained through: face-to-face interviews (socio-demographic and food frequency questionnaire), clinical assessments (thyroid size, and hyper/hypothyroidism) and biochemical analysis (urine and blood serum). A total of $677 \mathrm{PW}$ responded in the study with a response rate of $90.2 \%$. Majority of the PW were at second gravida, aged 25-29 years old and of Malay ethnicity. The methodology used in this study was based on international guidelines which may provide state's estimates. All the necessary steps were taken into consideration to ensure valid and reliable findings on current iodine status among PW.
\end{abstract}

Copyright $\odot 2019$ Institute of Advanced Engineering and Science. All rights reserved.

\section{Corresponding Author:}

Lim Kuang Kuay,

Centre for Occupational Health Research,

Institute for Public Health, Ministry of Health,

Bandar Setia Alam, 40170, Selangor, Malaysia.

E-mail: limkuangkuay@gmail.com

\section{INTRODUCTION}

Iodine, an essential nutrient for thyroid hormone thyroxine (T4) and triiodothyronine (T3) production, is essential for normal growth and development [1]. Adequate iodine intake is essential for the production of thyroid hormones. The body of a healthy adult contains about 10-20 mg of iodine which on average $70-80 \%$ (8-15 $\mathrm{mg}$ of iodine) is stored in thyroid gland [2]. The recommended daily iodine intake criteria for pre-school children, adults and pregnant women are $90 \mathrm{ug} / \mathrm{day}, 150 \mathrm{ug} / \mathrm{day}$ and $250 \mathrm{ug} / \mathrm{day}$, respectively [3]. Insufficient supply of iodine results in inadequate thyroid hormone production which may have multiple effects on human growth and development, collectively termed iodine deficiency disorders (IDD) [4].

Worldwide, IDD is a major public health problem which affects human population from early foetal life to adulthood [5]. IDD can affect anyone of any age, with the most vulnerable high-risk group for IDD in 
pregnant women (PW) [6]. Iodine requirement is high during pregnancy, it may increase by $50 \%$ due to physiological changes and increased in maternal thyroxine production [7]. Severe and long-term iodine deficiency in PW results in serious adverse effects such as increasing risk of stillbirths, abortions and congenital abnormalities [8]. However, this problem can be corrected by mass application of iodized salt [9], also known as universal salt iodization (USI). Since the largest part of iodine intake is usually from household salt [10], USI is the optimal way to ensure sufficient intake of iodine by all individuals [11], and the international experience has convincingly demonstrated that USI is the most reliable, safe and cost-effective way to eliminate IDD [12]. Normally, an average daily salt intake in population ranged between $5-15 \mathrm{~g}$ /day may provide approximately $150 \mu \mathrm{g}$ of iodine/day after taking into account the lose of iodine in iodized salt due to climatic and storage factors [13].

In Sarawak, IDD is common in most of its interior areas due to the predominantly mountainous terrain and heavy rain. However, with rapid ongoingsocio-economic development over the past 20 years and the emerging of new townships, outside foods including seafood are now more widely available to the once remote and inaccessible areas [14-15]. In 2008, a National IDD survey conducted in Malaysia revealed the median urinary iodine concentration (mUIC) of school children in Sarawak was at borderline-adequate level $(101.9 \mu \mathrm{g} / \mathrm{L})$, and iodine status among children from rural areas remains inadequate (mUIC, $96.6 \mu \mathrm{g} / \mathrm{L})$ [16]. Hence, within the same year, a legislation on USI was enacted in Sarawak which required all salt for human consumption to be iodized with iodine content of $20 \mathrm{ppm}$ to $40 \mathrm{ppm}$ [17].

In 2015, a state-wide IDD study among pregnant women (PW) in Sarawak revealed an inadequate iodine status among the study participants despite the implementation of the mandatory USI since 2008. The mUIC of the PW in this study was $105.6 \mu \mathrm{g} / \mathrm{L}$, indicating iodine deficiency and the distribution of urinary iodine (UI) levels showed that a total of $330 \mathrm{PW}(65.0 \%)$ had UIC $<150 \mu \mathrm{g} / \mathrm{L}$ [18]. The present findings which reported that PW residing in areas where people generally have sufficient iodine intake may still experience IDD were in concordance with those of other studies[19-22]. Thus, a comprehensive study is warranted to provide Sarawak State Health Department (SSHD) with more relevant information on the current status of IDD among pregnant women in Sarawak after ten years of mandatory USI implementation since 2008. This article aims to describe the methodology used in conducting this study on assessment of risk of iodine deficiency among pregnant women in Sarawak, Malaysia.

\section{RESEARCH METHOD}

\subsection{Scope of the study}

The state-wide assessment of risk of iodine deficiency among pregnant women (PW) in Sarawak, Malaysia was a collaborative study between Institute for Public Health, National Institutes of Health, Ministry of Health Malaysia and the Sarawak State Health Department (SSHD), Ministry of Health Malaysia. The survey was targeted to pregnant women in the first trimester who registered and received antenatal care in government maternal child health care clinics (MCHCs).

\subsection{Sampling frame and sample size}

The sampling frame used was the 2016 list of all the government MCHCs in Sarawak. Based on the frame, there were $267 \mathrm{MCHCs}$ in the state. The sampling did not include PW from private hospitals. The sampling units for the survey were all the MCHCs in the 12 divisions in Sarawak. A total of $30 \mathrm{MCHCs}$ were considered sufficient (recommended minimum number of cluster to ensure a relatively valid prevalence estimate) due to limited resources and logistics feasibility [3]. These MCHCs were selected based on probability proportional to size (PPS) method which involved 4 steps: i. Listing the MCHCs to be sampled, ii. Writing the population size (based on total post-natal mother visit to MCHCs in 2016). iii. Cummulating this size measures, and iv. Taking systematic random sample of the required size from the cummulated list [23]. The PW sample size was calculated using an appropriate formula on the basis of the ability to estimate the prevalence of IDD with adequate precision, and was inflated to cater for estimated design effect and non-response [24-25]. The sample size of the study was calculated based on $95 \%$ confidential interval (CI), relative precision of 5\%, design effect of 2 and non-response rate of $20 \%$. The anticipated prevalence of IDD for the Sarawak was $65.0 \%$, based on the prevalence reported, the total sample size required was 737 (round up to 750). Therefore, the sample size per MCHC will be $25(750 / 30=25)$. The sample size also exceeds the WHO recommended sample size of 300 for reliable assessment of iodine status of population [26]. The WHO Expanded Programme on Immunization (EPI) surveys approach was used to randomly select the first respondent and then, subsequent respondents were chosen until the required number of PW was met [23]. The inclusion criteria for participation in this study included PW of first trimester (first 12 weeks of gestation), aged 18 years and above, and were attending antenatal care appointments at the 30 selected MCHCs between 15 July 2018 and 15 October 2018. 


\subsection{Study instrument}

All required data were obtained through: interviews on mother's socio-demographic and food frequency intake, thyroid size examination, hyper/hypothyroidism assessment and analysis of urine iodine, blood serum and household salt from the study respondents. The face-to-face interview of IDD survey questionnaires took approximately 30 minutes to complete.

\subsection{Socio-demographic and food frequency intake}

The demographic questionnaire included questions related to personal information such as age, gender and ethnicity. The consumption patterns of iodine-rich foods over the past one month (daily, weekly and monthly) were measured using semi-quantitative food frequency questionnaire (FFQ) adopted from the National IDD Survey 2008 [16]. It included 11 iodine-rich food items such as fish and fish products, other seafood and seaweed, 7 goitrogen-rich food items such as tubers and cabbage. A food album containing pictures of commonly eaten iodine-rich food were used to help the respondents identify the food items. Household utensils such as cup and spoon were also used to help the respondents quantify the amount of food taken.

\subsection{Thyroid size}

Enlargement of the thyroid gland in PW was assessed by the trained staff nurses and graded according to grade 0,1 and 2 [3]. Grade 0; no goitre, grade 1; an enlarged thyroid that is palpable but not visible when the neck is in the normal position. Grade 2, a swelling in the neck that is visible when the neck is in a normal position. A prevalence rate of 0-4.9 is considered as none, 5.0\%-19.9\% as mild, $20.0 \%-29.9 \%$ as moderate, $\geq 30.0 \%$ as severe IDD [3].

\subsection{Iodine in urine}

Spot urine samples were collected using urine containers from all the respondents by trained medical laboratory assisstants. The samples were kept in the polystyrene container before trasported to the IDD Laboratory in Kota Kinabalu, Sabah. The samples were stored at $-18^{\circ} \mathrm{C}$ until analysis. Urinary iodine determination was done using in-house modified microplate method based on manual digestion with ammonium persulfate followed by the calorimetric determination of the Sandel-Kolthoff reaction by using 96-multiwell plates and an absorbance microplate reader at $405 \mathrm{~nm}$ [27]. PW with urinary iodine concentration (UIC) of $<150,150-249,250-499$, and $\geq 500 \mu \mathrm{g} / \mathrm{L}$ were considered as having insufficient, adequate, more than adequate, or excessive iodine levels, respectively [3].

\subsection{Iodine in blood}

Venous blood samples $(10.0 \mathrm{ml})$ were collected into plain vacutainer tubes by trained staff nurses. Then, the blood serum was separated and kept in $-20^{\circ} \mathrm{C}$ freezer at the nearby hospital laboratory at the end of the day by medical laboratory assisstants. All samples were properly packed and labeled, kept in polystyrene boxes containing ice before being transported to the private laboratory in Sarawak for further analysis. The Thyroid Stimulating Hormone (TSH) status was determined by using commercial Architect TSH 7K62 [28]. Free T4 and free T3 status were determined using commercial Architect Free Thyroxine (free T4) 7K65 [29] and Architect Free Triiodothyronine (free T3) 7K63 [30], respectively. Thyroperoxidase antibody (TPOAb) status was determined using commercial Architect Anti-TPO 2K47 [31] and Thyroglobulin antibody (TGAb) status was determined using commercial Architect Anti-Tg 2K46 [32]. Normal reference ranges established by the commercial kit manufacturer were used for assessing thyroid dysfunction: TSH (0.35-4.94 mIU/L, free T4 (9.0-19.1 pmol/L), free T3 (2.63-5.71 pmol/L), TPOAb $(<5.61 \mathrm{IU} / \mathrm{mL})$ and TGAb $(<4.11 \mathrm{IU} / \mathrm{mL})[28-32]$.

\subsection{Iodine in salt}

All the PW were also asked to bring approximately $80 \mathrm{~g}$ of salt from their respective homes in self-sealing polythene bags. The samples were properly packed and labeled before being transported to the Nutrition Unit, Institute for Medical Research, Kuala Lumpur for analysis. The presence of iodine in salt was tested using rapid test kits (RTKs) developed by Institute for Medical Research. While, the level of iodine concentration in salt was determined using iodimetric titration method [33]. Titration is one of the most accurate analytical methods available and this 'gold standard' analytical method is recommended for factory quality assurance and in research studies [34]. Households coverage with iodized salt and monitoring quality of salt iodization are important key indicators in the implementations of USI programs. To ensure sustainable IDD programme in a country, it is recommended that at least $90 \%$ of households using adequately iodised salt which contains 15 parts per million or more [3]. 


\subsection{Anthropometric measurements}

Anthropometric measurements were weight $(\mathrm{kg})$ and height $(\mathrm{cm})$. TANITA HD-319 digital weighting equipment was used to measure body weight to the nearest $0.1 \mathrm{~kg}$. Without wearing shoes, respondents are required to stand upright, head and eyes straight. While, the measurement for height were taken to the nearest $0.1 \mathrm{~cm}$ using SECA 213 portable stadiometer. The respondents were required to stand upright without shoes, hips and shoulders in a straight line, head and eye is straight. Measurements were done in duplicate, and the mean was recorded as the final reading. Body mass index (BMI) was calculated by weight in kilograms divided by height in metres squared. The term underweight refers to BMI $<18.5 \mathrm{~kg} / \mathrm{m}^{2}$, normal (BMI $=18.5-24.9 \mathrm{~kg} / \mathrm{m}^{2}$ ), while overweight and obese are classified as having BMI within $25.0-29.9 \mathrm{~kg} / \mathrm{m}^{2}$ and $\geq 30 \mathrm{~kg} / \mathrm{m}^{2}$, respectively [35].

\subsection{Hyper/hypothyroidism assessment}

Staff nurse of the data collection team carried out face-to-face interviews with the PW and conducted physical assessment to gather information on hyper/hypothyroidism status. This assessment consists of 12 items which covered: a) Proximal muscle weakness/hyper-reflexia. b) Warm/Sweat palms. c) Hand sweating. d) Fine tremours (finger). e) Lid retraction/lid lag. f) Resting tachycardia. g). Apathy/lethargy. h). Facial puffiness. i). Slow speech. j) Hoarse voice. k) Cold intolerance. l) Fat/obese, and $\mathrm{m}$ ) Constipation.

\subsection{Field implementation and ethical consideration}

Approval was obtained from the Medical Research and Ethic Committee, Ministry of Health Malaysia (NMRR-17-2932-39316) and the head of department in all respective MCHCs. A total of 12 data collection teams were formed, and in each team, one nutritionist as team leader and assisted by 2 staff nurses and one medical laboratory assisstant. A training course was conducted to familiarize the teams with the questionnaire used and samples collection techniques. Information sheets and consent forms were made available for every respondent. All individual information was kept confidential. A dummy identification was given to each respondent instead of his or her name to make sure the study was anonymous.

\subsection{Quality control}

Quality control of the whole survey was done at various stages of the study to ensure data collected was of high-quality. During field data collection, team leader was given responsibility to conduct the interviews and was given responsibility to supervise the whole data collection processes. At the central level, the progress of data collection for all MCHCs was monitored closely by the officer from the Institute for Public Health on a weekly basis. In addition, all the submitted questionnaires had undergone various checks by the data processing team.

\subsection{Data entry and analysis}

All data entry activities were centralized at Institute for Public Health which started from receiving questionnaire from the field until hand over of the clean dataset to data analysis team. Data processing activities were done based on the type of questionnaire. The data entry was done using an excel database by data puncher. All data that were keyed into database were verified by a verifier. SPSS version 21 was used for data analysis. The data was then checked and cleaned for quality control purposes. Descriptive statistic was used to illustrate the social demographic of the respondents. Analysis was done according to the objectives of the study. Complex sample analysis procedures were used in the analysis and was carried out at $95 \%$ confidence interval.

\section{RESULTS AND DISCUSSIONS}

All selected MCHCs participated in the survey (100\% response rate) and a total of 677 respondents responded to the survey, with an overall response rate of $90.2 \%$. Out of $30 \mathrm{MCHCs}$ surveyed, a total of 21 MCHC observed a better response rate of $100 \%$. However, there were a few MCHCs showed a response rate of less than 50\% such as KK Batu Kawa (40\%), KK Spaoh (44\%), KK Asajaya (48\%), and KK Tatau (48\%) as shown in Table 1.

The respondents comprised of $677 \mathrm{PW}$ aged between 18 to 45 years (mean $\pm \mathrm{SD}, 28.6 \pm 5.3$ ) and approximately $35 \%$ of the respondents were from age group 25-29 years old. By ethnicity, majority of the respondents were Malays (35.2\%), followed by Iban (29.5\%) and Chinese (13.0\%). In terms of gravida (number of pregnancy), about $31 \%$ of PW were in their second gravida and $28.5 \%$ were in their first gravida as shown in Table 2. 
Table 1. Number of respondents responsed to the survey, by Division and MCHCs

\begin{tabular}{|c|c|c|c|}
\hline \multirow{2}{*}{ division \& MCHCs } & \multicolumn{2}{|c|}{ number of respondents } & \multirow{2}{*}{$\begin{array}{c}\text { percentages } \\
(\%)\end{array}$} \\
\hline & invited & response & \\
\hline Kuching & & & \\
\hline KK Petra Jaya & 25 & 24 & 96.0 \\
\hline KK Batu Kawa & 25 & 10 & 40.0 \\
\hline MCHC Sekama & 25 & 25 & 100.0 \\
\hline MCHC Gita & 25 & 25 & 100.0 \\
\hline KK Kota Sentosa & 25 & 25 & 100.0 \\
\hline $\begin{array}{c}\text { KKIA Kota Padawan } \\
\text { Samarahan }\end{array}$ & 25 & 25 & 100.0 \\
\hline KK Kota Samarahan & 25 & 25 & 100.0 \\
\hline MCHC Sebisak & 25 & 25 & 100.0 \\
\hline K1M Samarindah & 25 & 15 & 60.0 \\
\hline $\begin{array}{l}\text { KK Asajaya } \\
\text { Serian }\end{array}$ & 25 & 12 & 48.0 \\
\hline KK Siburan & 25 & 25 & 100.0 \\
\hline $\begin{array}{l}\text { KK Serian } \\
\text { Sri Aman }\end{array}$ & 25 & 25 & 100.0 \\
\hline $\begin{array}{l}\text { KK Sri Aman } \\
\text { Betong }\end{array}$ & 25 & 25 & 100.0 \\
\hline KK Kabong & 25 & 25 & 100.0 \\
\hline $\begin{array}{l}\text { KK Spaoh } \\
\text { Sarikei }\end{array}$ & 25 & 11 & 44.0 \\
\hline KK Bintangor & 25 & 25 & 100.0 \\
\hline $\begin{array}{l}\text { KK Sarikei } \\
\text { Mukah }\end{array}$ & 25 & 25 & 100.0 \\
\hline $\begin{array}{l}\text { KKIA Dalat } \\
\text { Sibu }\end{array}$ & 25 & 25 & 100.0 \\
\hline KK Jalan Oya & 25 & 25 & 100.0 \\
\hline KK Lanang & 25 & 25 & 100.0 \\
\hline $\begin{array}{c}\text { KKIA Kanowit } \\
\text { Kapit }\end{array}$ & 25 & 25 & 100.0 \\
\hline KK Kapit & 25 & 25 & 100.0 \\
\hline $\begin{array}{l}\text { KK Song } \\
\text { Bintulu }\end{array}$ & 25 & 18 & 72.0 \\
\hline KK Bintulu & 25 & 25 & 100.0 \\
\hline $\begin{array}{l}\text { KK Tatau } \\
\text { Miri }\end{array}$ & 25 & 12 & 48.0 \\
\hline KK Tudan & 25 & 24 & 96.0 \\
\hline KKIA Miri & 25 & 26 & 104.0 \\
\hline $\begin{array}{l}\text { KKIA Tmn Tunku } \\
\text { Limbang }\end{array}$ & 25 & 25 & 100.0 \\
\hline KKIA Limbang & 25 & 25 & 100.0 \\
\hline KK Lawas & 25 & 25 & 100.0 \\
\hline Total & 750 & 677 & 90.2 \\
\hline
\end{tabular}

In conducting a state-wide survey among PW in Sarawak, sampling from government MCHCs was considered the best feasible approach to obtain a representative sample of PW in Sarawak. Based on the Ministry of Health, Malaysia annual report, the number of government MCHCs represents about $98 \%$ of all the MCHCs in Sarawak and, the delivery rate in government MCHCs was more than 95\% [18]. With this high rates, a representative sample of PW in Sarawak can be obtained from the government MCHCs. Due to the small proportion of private MCHCs in Sarawak, we decided to exclude private MCHCs in the survey and this exclusion would not make any significant effect on the findings. The strength of the study is the use of appropriate sampling method which involved a representative sample of respondents from all divisions in Sarawak. The samples size calculation also take into consideration of few factors such as prevalence, margin of error, design effect and estimated response rate [25]. The response rate of $90.2 \%$ in this study was considered high. The good response rate could be due to several factors including good collaborations and supports from Sarawak State Health Department (SSHD). In addition, the data collection was conducted by SSHD staffs who are well verse with the local language and culture. However, there were a few MCHCs showed low response rates, especially from small MCHCs. It's noted that during the period of data collection, in these MCHCs with low response rates, there has been quite a number of PW whose gestational periods has been exceeding 12 weeks (first trimester) when they came for check up. Thus, they are not eligible for the survey. 
Table 2. Socio-demographic characteristics of pregnant women in Sarawak

\begin{tabular}{ccc}
\hline characteristics & number of respondents & percentages (\%) \\
\hline Overall & 677 & 100.0 \\
Age (years) & 178 & \\
$\leq 25$ & 232 & 26.3 \\
$25-29$ & 188 & 34.3 \\
$30-34$ & 79 & 27.8 \\
$\geq 35$ & & 11.7 \\
Ethnicity & 200 & \\
Iban & 238 & 29.5 \\
Malay & 88 & 35.2 \\
Chinese & 49 & 13.0 \\
Bidayuh & 41 & 7.2 \\
Melanau & 61 & 6.1 \\
Others & & 9.0 \\
1 & 193 & \\
2 & 208 & 28.5 \\
Gravida (number of pregnancy) & 130 & 30.7 \\
$\geq 4$ & 146 & 19.2 \\
\hline
\end{tabular}

\section{CONCLUSION}

This IDD study among PW aimed at providing population-based data on the IDD status of PW in Sarawak. The survey was planned with the goal of obtaining the latest data to support Ministry of Health, Malaysia in reviewing and planning the IDD program in Sarawak. To ensure the data collected are of high quality and validity, all the necessary steps have been taken, starting from planning, determination of sample size, sampling design, data collection techniques, and quality control of data collected. The findings of this study will enable the Ministry of Health, Malaysia to evaluate the impact of the USI among pregnant women in Sarawak and make necessary improvement to the present national programme.

\section{ACKNOWLEDGEMENTS}

The research was funded by the Ministry of Health Malaysia. We wish to acknowledge the Director General of Health Malaysia for permission to publish this paper. Special thanks to Sarawak State Health Department for providing health staffs to involve in this survey.

\section{REFERENCES}

[1] American Thyroid Association. Hypothyroidism: A booklet for patient and their families. Falls Church: American Thyroid Association, p. 598-606, 2013.

[2] Ristic-Medic D, Glibetic M. Iodine: Physiology in encyclopedia of feed and health. University of Belgrade, Belgrade,.p. 444-45, 2016.

[3] WHO/UNICEF/ICCIDD. Assessment of iodine deficiency disorders and monitoring their elimination. $3^{\text {rd }}$ ed. France: World Health Organization,. p. 7-10, 2007.

[4] Zimmermann MB. The role of iodine in human growth and development. Seminar in cell \& Dev Biol., 22:645-52, 2011.

[5] Hetzel B. Vanquishing iodne deficiency disorders. Lancet., 381, 2013.

[6] Trumpff C, Schepper JD, Tafforeau, Oyen HV, vanderfaeillie J, Vandevijvere S. Mild iodine deficiency in pregnancy in Europe and its consequences for cognitive and psychomotor development of children: A review. $J$. Trace Elem Med \& Biol., 27:174-83, 2013.

[7] Zimmermann MB. The effects of iodine deficiency in pregnancy and infancy. Paediatr Perin Epidemiol., 26 (suppl 1):108-17, 2012.

[8] Boonstra AM, jaiswal N. Iodine deficiency in pregnancy, infancy and children and its consequences for brain development. Best Pract Res Clin Endocrinol Metab., 24:29-38, 2010.

[9] Caron P. Neurocognitive outcomes of children secondary to mild iodine deficiency in pregnant women. Ann Endocrinol., 76: 248-52, 2015.

[10] Anaforoglu I, Algun E, Incecayir O, Topbas M, Erdogan MF. Iodine status among pregnant women after mandatory salt iodisation. Br J Nutr., 115:405-10, 2016.

[11] Andersson M, de Benoist B, Roger L. Epidemiology of iodine deficiency: Salt iodisation and iodine ststus. Best Pract Res Clin Endocrinol Metab., 24:1-11, 2010.

[12] Gregory G, IDD elimination in Russia: challenges and solution. Zurich: IDD Newsletter; May. p.1-6, 2008.

[13] UNICEF. Sustainable of iodine deficiency. New York: The United nations of Children's Fund,. p. 5-7, 2008.

[14] Lim KK, Jambai E, Chan YY, Teh CH, Hasimah I, Lim KH, Kee CC. Iodine status after a 3-year universal salt iodisation in Sarawak, Malaysia. Int J Pub Health Res., 5(2): 631-36, 2015. 
[15] Kiyu A. Iodine deficiency disorders in Sarawak, Malaysia. Asia Pac J Clin Nutr., 7(3/4):256-61, 1998.

[16] Rusidah S, Wan Nazaimoon WM, Ahmad Ali Z, Nor Syamlina CAR, Suhaila AG, Tahir A. Iodine deficiency status and iodised salt consumption in Malaysia: Findings from a national iodine deficiency disorders survey. Asia Pac J Clin Nutr., 19(14):578-85, 2010.

[17] Government of Malaysia. Food Act and Regulation.Kuala Lumpur: MDC Publishers,. p. 13-15, 2013.

[18] Sarawak State Health Department. Survey of iodine deficiency disorders among pregnant women in Sarawak, State Health Department of Sarawak. p. 24-7, 2016.

[19] Kuang Kuay Lim, Ying Ying Chan, Chien Huey Teh, Hasimah Ismail, Rafidah Yusof, Jamail Muhi, Kuang Hock Lim, Foo Leng Huat Foo. iodine status among pregnant women from selected rural divisions in Sabah, Malaysia. Asia Pac J Clin Nutr.,26 (5):861-66, 2017.

[20] Torre EM, Alvarez ED, Artal AR, Gutierrez LS, caballero MGR, Blanco JA, Naya LD, Fernandez JCF. Iodine nutrition in pregnant women in the Oviedo area. Is iodine supplementation required?. Endocrinol Nutr. 2014;61(8):404-09.

[21] Caldwell KL. Makhmudov A. Ely E. Jones RL. Wang RY. Iodine Status of the U.S. Population, National Health and Nutrition Examination Survey, 2005-2006 and 2007-2008. Thyroid., 21(4): 419-27, 2011.

[22] Marchioni E, Fumarola A, Calvanese A, Piccirilli F, Tommasi V, Cugini P, Ulisse S, fanelli FR, D'Armiento M. Iodine deficiency in pregnant women residing in an area with adequate iodine intake. Nutrition., 24:458-61, 2008.

[23] World Health Organization. Training for mid-level managers (MLM): The EPI coverage survey. Geneva: World Health Organization,. p. 6-15, 2008.

[24] Naing NN.A practical guide on determination od sample size in health sciences research. Kota Bharu: Universiti Science Malaysia,. p. 1-20, 2010.

[25] Naing L, Winn T, Rusli BN. Practical issues in calculating the sample size for prevalence studies. Arch Orofac Sci., 1:9-14, 2006.

[26] Condo D, Huyhn D, Anderson AJ, Skeaff S, Ryan P makrides M, et.al. Iodine status of pregnant women in South Australia after mandatory iodine fortification of bread and the recommendation for iodine supplementation. Matern Child Nutr., 13(4):1-8, 2016.

[27] Husniza H, Wan Nazaimoon WM. A cost effective modified micro method for measuring urine iodine. Tropic Med., 23(1):109-15, 2006.

[28] Abbott laboratories.. Architect TSH 7K62. Longford: Abbott Ireland Diagnostics. p. 1-7, 2015.

[29] Abbott laboratories. Architect Free T4 7K65. Longford: Abbott Ireland Diagnostics. p. 1-6. 2017.

[30] Abbott laboratories. Architect Free T3 7K63. Longford: Abbott Ireland Diagnostics., p. 1-5, 2015.

[31] Abbott laboratories. Architect Anti-TPO 2K47. USA: Abbott laboratories. p. 1-6, 2005.

[32] Abbott laboratories. Architect Anti-Tg 2K46. USA: Abbott laboratories. p. 1-7, 2006.

[33] Sullivan KM, Houston R, Gorstein J, Cervinskas J. Monitoring universal salt iodization programmes. Atlanta: Micronutrient Initiative,. p.15-8, 1995.

[34] Myers NM, Strydom EE, Sweet J, Sweet C, Spohrer R, Ali Dhansay M, Lieberman M. SaltPAD: a new analytical tool for monitoring salt iodization in low resource setting. Nanobiomed., 3(5):1-9, 2016.

[35] Doherty DA, Magan EF, Francis J, Morrison JC, Newnham JP. Pre-pregnancy body mass index and pregnancy outcomes. Int J Gynaecol Obstet.,95:242-47, 2006. 